\title{
The ARMC5 gene shows extensive genetic variance in primary macronodular adrenocortical hyperplasia
}

\author{
Ricardo Correa ${ }^{1,+}$, Mihail Zilbermint ${ }^{1,+}$, Annabel Berthon', Stephanie Espiard', \\ Maria Batsis' ${ }^{1}$, Georgios Z Papadakis², Paraskevi Xekouki ${ }^{1}$, Maya B Lodish', \\ Jerome Bertherat ${ }^{3}$, Fabio R Faucz ${ }^{1,4, *}$ and Constantine A Stratakis ${ }^{1, *}$ \\ ${ }^{1}$ Section on Endocrinology and Genetics, Program on Developmental Endocrinology and Genetics, Eunice Kennedy \\ Shriver National Institute of Child Health and Human Development, National Institutes of Health, NIH-Clinical \\ Research Center, 10 Center Drive, Building 10, Room 1-3330, MSC1103, Bethesda, Maryland 20892, USA, \\ ${ }^{2}$ Department of Radiology and Imaging Sciences, National Institutes of Health (NIH), Clinical Center, Bethesda, \\ Maryland 20892, USA, ${ }^{3}$ Department of Endocrinology, Metabolism, and Diabetes, Institut National de la Santé et de \\ la Recherche Médicale (INSERM) Unit 1016, Institut Cochin, Centre National de la Recherche Scientifique (CNRS) \\ UMR 8104, 75014 Paris, France and ${ }^{4}$ Group for Advanced Molecular Investigation, Graduate Program in Health \\ Science, Medical School, Pontificia Universidade Catolica do Paraná, Curitiba, Paraná, Brazil \\ ${ }^{t} \mathrm{R}$ Correa and $\mathrm{M}$ Zilbermint share the first authorship of this manuscript \\ ${ }^{*} \mathrm{~F}$ R Faucz and C A Stratakis share the senior authorship of this manuscript
}

Correspondence should be addressed to F R Faucz Email

fabio.faucz@nih.gov

\begin{abstract}
Objective: Primary macronodular adrenal hyperplasia (PMAH) is a rare type of Cushing's syndrome (CS) that results in increased cortisol production and bilateral enlargement of the adrenal glands. Recent work showed that the disease may be caused by germline and somatic mutations in the ARMC5 gene, a likely tumor suppressor gene (TSG). We investigated 20 different adrenal nodules from one patient with PMAH for ARMC5 somatic sequence changes.

Design: All of the nodules were obtained from a single patient who underwent bilateral adrenalectomy. DNA was extracted by standard protocol and the ARMC5 sequence was determined by the Sanger method.

Results: Sixteen of 20 adrenocortical nodules harbored, in addition to what appeared to be the germline mutation, a second somatic variant. The p.Trp476* sequence change was present in all 20 nodules, as well as in normal tissue from the adrenal capsule, identifying it as the germline defect; each of the 16 other variants were found in different nodules: six were frame shift, four were missense, three were nonsense, and one was a splice site variation. Allelic losses were confirmed in two of the nodules.

Conclusion: This is the most genetic variance of the ARMC5 gene ever described in a single patient with PMAH: each of 16 adrenocortical nodules had a second new, 'private,' and - in most cases - completely inactivating ARMC5 defect, in addition to the germline mutation. The data support the notion that ARMC5 is a TSG that needs a second, somatic hit, to mediate tumorigenesis leading to polyclonal nodularity; however, the driver of this extensive genetic variance of the second ARMC5 allele in adrenocortical tissue in the context of a germline defect and PMAH remains a mystery.
\end{abstract}

\section{Introduction}

Primary macronodular adrenal hyperplasia (PMAH), also known in the past as bilateral macronodular adrenal hyperplasia or adrenocorticotropin (ACTH)-independent macronodular adrenal hyperplasia, is a rare type of
Cushing's syndrome (CS) and is associated with bilateral enlargement of the adrenal glands. It accounts for $<1 \%$ of all endogenous cases of CS (1). The disease was first described by Kirschner et al. (2) in a single patient with 
ACTH-independent CS that developed over many years and was caused by apparently autonomously functioning multiple adrenal macronodules in both glands. In PMAH, there is an aberrant adrenal function of G-protein coupled receptors that can lead to cell proliferation and abnormal regulation of steroidogenesis (3). Recently, Louiset et al. (4) suggested that the hypercortisolism associated with PMAH appears to be corticotropin-dependent, which challenged the notion of an ACTH-independent disorder. They found expression of proopiomelanocortin mRNA in all samples of hyperplastic adrenal tissue, and ACTH was detected in steroidogenic cells disseminated throughout the adrenal specimens. The release of adrenal ACTH was stimulated by ligands of aberrant membrane receptors but not by ACTH-releasing hormone or dexamethasone; in addition, an ACTHreceptor antagonist significantly inhibited in vitro cortisol secretion (4).

Although several patients have been described with mutations in various genes $(5,6)$, it was believed that most cases of PMAH were sporadic. An autosomal dominant pattern of transmission was suggested for the familial cases $(1,5,6,7)$. Most recently, Assie et al. (8) found that the disease is caused by germline mutations in the armadillo repeat containing 5 (ARMC5) gene, in addition to somatic mutations in the tumor tissue; other studies also showed frequent ARMC5 mutations in PMAH $(7,8,9)$. These findings confirmed previous data that suggested that the different nodules of PMAH represent products of polyclonal proliferative events that were propagated by changes in micro-RNAs, 17q22-24 losses and the involvement of multiple signaling pathways including those of cAMP and Wnt $(10,11,12,13)$. ARMC5 mutations were found in some of the tissues used in these studies, as well in previously described families with PMAH $(14,15)$. The ARMC5 gene appears to function as a tumor suppressor gene (TSG) and is located on chromosome 16 (16p11.2) (8). However, little is known about the way tumors form due to ARMC5 loss, and more importantly nothing is known about what drives polyclonality in PMAH.

In the present investigation, we report a patient with PMAH caused by a germline ARMC5 mutation, who demonstrated extensive genetic diversity at the tissue level. To our knowledge, this phenomenon has not been described in other benign tumor disorders besides PMAH and is akin to what is seen in the context of malignancypredisposing lesions, such as for example multiple colonic polyps of patients with hereditary predisposition to colon cancer (16).

\section{Subjects and methods}

\section{Clinical research protocol}

The patient was admitted to the National Institute of Health (NIH) Warren Magnuson Clinical Center for the work-up and treatment of her PMAH under research protocol 00-CH-0160 (clinical trial registration number of NCT00005927). The Eunice Kennedy Shriver National Institute of Child Health and Human Development Institutional Review Board approved this study, and informed consent was obtained from the patient.

\section{Hormone assays}

Plasma cortisol and ACTH levels, 24-h urinary free cortisol (UFC) and 17-OH steroids were measured as described elsewhere (14).

\section{ARMC5 sequencing analysis}

DNA was obtained from 20 different adrenal nodules that were dissected from the surgically obtained specimen; the capsule of the adrenal gland was used for normal tissue. DNA was extracted according to manufacturer protocols (Qiagen). ARMC5 (OMIM: 615549; Chr16:31,470,317$31,478,488$ - GRCh37/hg19) was analyzed in 20 different adrenal nodules and in one piece of normal tissue. The complete ARMC5-coding and surrounding intronic sequence, harboring all known isoforms, of these adrenal nodules and normal tissue was amplified using the conditions previously described (14). Each PCR product was amplified using BigDye Terminator V3.1 (Life Technologies) purified using ZR DNA Sequencing Clean-up Kit (Zymo Research, Irvine, CA, USA) and analyzed by classical bidirectional Sanger sequencing. For the variations nomenclature, the main frequent isoform in the literature (NM_001105247.1) was used.

\section{In silico analysis and immunohistochemistry}

The in silico software tool 'Polymorphism Phenotyping v2' (PolyPhen-2) was utilized to predict the pathogenic potential of the identified missense variants in ARMC5, as previously described (14). ARMC5 immunohistochemistry (IHC) was performed on tissues embedded in paraffin as previously described (14). Unfortunately, additional slides were not available in order to look for expression of ARMC5 in the individual nodules corresponding to the somatic variants that were identified. 


\section{D computed tomography of adrenal glands}

Surface rendering of the adrenal nodules was produced after precisely delineating them from computed tomography (CT) scans in a semi-automated way. Afterwards, segmented adrenal surfaces were fused with the volumetric rendering of the abdomen region from CT images.

\section{Results}

\section{Case presentation}

A 42-year-old Caucasian female with no significant past medical history (including absence of meningioma and/or other tumors) presented to the NIH Clinical Center for evaluation of possible CS. Her medical history included secondary amenorrhea since the age of 38 , a $12 \mathrm{~kg}$ weight gain over the previous 2 years, hirsutism, proximal muscle weakness, easy bruising and thinning of the skin. Family history was relevant for the presence of a meningioma in her father, but no other cancers or known CS. The biochemical evaluation revealed elevated 24 -h UFC $(270 \mu \mathrm{g} / 24 \mathrm{~h}$, reference range $8-77 \mu \mathrm{g} / 24 \mathrm{~h}$ ), elevated late-night serum cortisol level $(21.8 \mu \mathrm{g} / \mathrm{dl})$ and suppressed ACTH $(<1 \mathrm{pg} / \mathrm{ml}$, reference range $9-52 \mathrm{pg} / \mathrm{ml}$ ). Serum cortisol remained unsuppressed after $1 \mathrm{mg}$ overnight dexamethasone test (at $21.9 \mu \mathrm{g} / \mathrm{dl}$, normal $<1.8 \mu \mathrm{g} / \mathrm{dl}$ ). CT imaging of the adrenal glands revealed bilateral multiple lobular masses more than $1 \mathrm{~cm}$ each in diameter, without evidence of cysts or microcalcifications (Fig. 1A and B). She was diagnosed with macronodular bilateral adrenal hyperplasia (BAH). Glucagon-, growth hormone-releasing hormone-, mixed

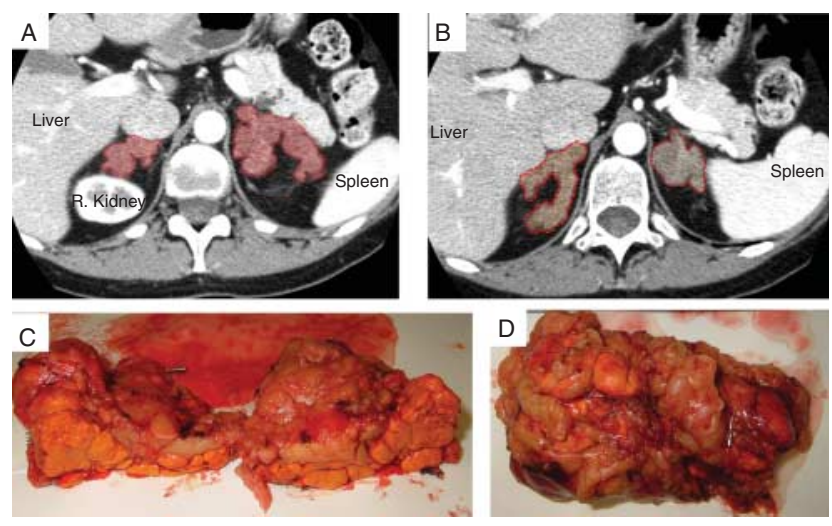

Figure 1

Computed tomography of adrenal glands with volumetric rendering of the abdomen region ( $A$ and $B$ ). Gross pathology of the left adrenal gland (C). Gross pathology of the right adrenal gland (D). meal-, postural and vasopressin tests were performed in order to evaluate for aberrant hormonal responses (Table 1); the only positive one was the postural test. She underwent uncomplicated laparoscopic bilateral adrenalectomy. The largest nodule in the left side was $1.7 \mathrm{~cm}$ (Fig. 1C); the largest in the right side was $2.5 \mathrm{~cm}$ (Fig. 1D). Pathology was consistent with PMAH: multi-nodular glands with homogenous, golden-yellow-colored nodules, with no necrosis or hemorrhages. Nodules contained predominantly clear cells with interspersed compact cells disposed in nest- and cord-like arrangement (Fig. 2). The patient was discharged home in good condition on oral hydrocortisone and fludrocortisone replacement therapy and remains well to this day.

\section{ARMC5 genetics and expression}

We identified one ARMC5 (NM_001105247.1) germline sequence variant that was present in all analyzed tissue and appeared to be the causative mutation; we also identified 14 somatic variants and two events consistent with losses of heterozygozity (LOH) in all 20 adrenal nodules (Fig. 3 and Supplementary Figure 1, see section on supplementary data given at the end of this article). The ARMC5 nonsense variant c. $1428 \mathrm{G}>\mathrm{A}$ (p.Trp476*) was present in all analyzed specimens, including tissue from the normal capsule. Other genetic defects were present in different nodules. Six of the variations were frameshift: c.327delC (p.Ala110Profs*27), c.346delT (p.Ser116Argfs*21), c.608delG (p.Ser203Thrfs*2), c.789_808del20 (p.Glu264Profs*5), c.1059_1080del22 (p.Cys353*), c.2444delG (p.Ala815Leufs*102); three were nonsense: c.807C $>$ A (p.Cys269*), c.1033C $>$ T (p.Gln345*), c.1059C >A (p.Cys353*); four were missense and resulted in amino acid substitutions: c. $247 \mathrm{G}>\mathrm{C}$ (p.Ala83Pro), c.1751T $>$ A (p.Val584Glu), c.2228C $>$ T (p.Ala743Val), c.2405C > G (p.Pro802Arg); one was a splice site: c.476-1G $>$ A; and in two nodules $\mathrm{LOH}$ was identified (Table 2). All sequence changes that were found in this patient were novel. Supplementary Figure 2 shows a 3D-CT with the lesions and the corresponding sequence variants found in each adrenal (left and right).

In silico analysis was performed for four somatic missense sequence variants and the prediction was that they were all likely damaging: p.Ala743Val, (score 0.703), p.Ala83Pro (score 1.000), p.Val584Glu (score 1.000), and p.Pro802Arg (score 1.000). It should be noted that scores vary from 0.000 to 1.000 , and a greater score indicates a higher probability to impair ARMC5 protein function (Table 2). 
Table 1 Different tests to evaluate aberrant hormone receptor regulation of cortisol secretion.

\begin{tabular}{|c|c|c|c|c|c|c|c|}
\hline \multirow[b]{2}{*}{ Test } & \multirow[b]{2}{*}{ Variable } & \multicolumn{6}{|c|}{ Time (min) } \\
\hline & & -15 & 0 & 30 & 60 & 90 & 120 \\
\hline \multirow[t]{3}{*}{ Postural $^{a}$} & Cortisol ( $\mu \mathrm{g} / \mathrm{dl})$ & 17.4 & 17.8 & 23.5 & 25.8 & 27.4 & 29.8 \\
\hline & Aldosterone (ng/dl) & $<1.5$ & $<1.5$ & 3.4 & 10.4 & 11.3 & 10.9 \\
\hline & Renin (ng/ml per h) & & $<0.6$ & & 0.8 & & 1 \\
\hline \multirow[t]{2}{*}{ Mixed Meal ${ }^{\mathrm{b}}$} & Aldosterone (ng/dl) & & 1.7 & $<1.5$ & $<1.5$ & $<1.5$ & $<1.5$ \\
\hline & Cortisol $(\mu \mathrm{g} / \mathrm{dl})$ & & 20.8 & 20.2 & 16.2 & 17 & 16 \\
\hline \multirow[t]{3}{*}{ GHRH } & Cortisol ( $\mu \mathrm{g} / \mathrm{dl})$ & & 19.8 & 22.1 & 22.9 & 22.9 & 21.7 \\
\hline & Aldosterone (ng/dl) & & $<1.5$ & 1.6 & 2.6 & 2.6 & 1.5 \\
\hline & Growth Hormone ng/ml & & 1.4 & 2.7 & 1.8 & 0.8 & 0.4 \\
\hline \multirow[t]{2}{*}{ Glucagon } & Cortisol $(\mu \mathrm{g} / \mathrm{dl})$ & 22 & 24 & 23.2 & 20.7 & 21.2 & 21.4 \\
\hline & Aldosterone (ng/dl) & $<1.5$ & 1.8 & 2.1 & 2.2 & 2.4 & 2.2 \\
\hline \multirow[t]{2}{*}{ Vasopressin } & Aldosterone (ng/dl) & & 1.7 & 3.1 & 5.6 & 5.8 & \\
\hline & Cortisol $(\mu \mathrm{g} / \mathrm{dl})$ & & 17.4 & 30.1 & 32.2 & 24.5 & \\
\hline
\end{tabular}

${ }^{\text {a }}$ Postural test positive.

${ }^{b}$ Mixed meal test negative.

IHC for ARMC5 was performed on our patient's samples and tissue from PMAH of a patient that did not have germline or somatic ARMC5 variants (Fig. 2). Cytoplasmic ARMC5 IHC was seen in the adrenal cortex of the patient with PMAH and no ARMC5 sequence alterations, but was almost absent in our patient, confirming its loss at the protein level.

\section{Discussion}

In this study we identified 15 different ARMC5 genecoding sequence alterations and two instances of $\mathrm{LOH}$ in a total of 20 analyzed nodules from the adrenals of a patient with PMAH. The ARMC5 mutation p.Trp476* was present in all analyzed adrenal nodules and the normal tissue, making it the germline defect, or first 'hit'; 14 of the nodules were found to have a second, nodule-specific somatic ARMC5 defect. In another 2, there was LOH but in four there was neither LOH nor another variant. Although larger genomic losses or other rearrangements that would not be detected by the methods used in this study cannot be excluded in these remaining four nodules, the finding is consistent with those reporting ARMC5 defects in patients with PMAH: not every nodule carried chromosome 16 LOH or another ARMC5 variant $(7,8,9)$. For the nodules where we did not identify a second mutation, they may either harbor a large deletion that cannot be identified by Sanger sequencing, have a mutation(s) in the middle of the intron changing the regular splicing of the RNA, have a mutation in the promoter region or, less likely, may reflect 'contamination' of the studied tumor tissue with genetic material from normal cells. Another possibility is that somatic mutations in other gene(s) contribute to tumor formation at least as strongly as the germline ARMC5 defect.

In the nodules where there are no other changes, does this suggest that, in some cases, ARMC5 haploinsufficiency alone can lead to adrenocortical proliferation? It is possible that this is the case, and until this can be tested in vitro or in animal models, we will not know for sure. However, it is clear that ARMC5 haploinsufficiency leads to predisposition to developing these adrenocortical tumors. Could ARMC5 deficiency lead to genomic instability as well? This is likely, as the number of genetic variations and the degree of overall genomic diversity of

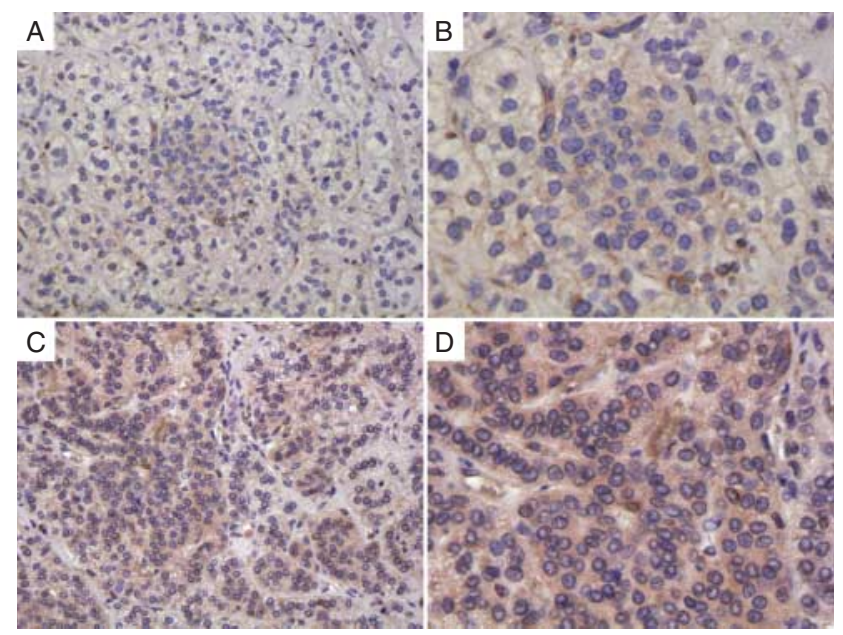

\section{Figure 2}

ARMC5 immunohistochemistry: staining with an ARMC5specific antibody was performed on a sample from the case presented here ( $A$ and $B$ ) and on tissues from a patient with $\mathrm{PMAH}$ and no ARMC5 germline or somatic variants ( $C$ and $\mathrm{D}$ ). 


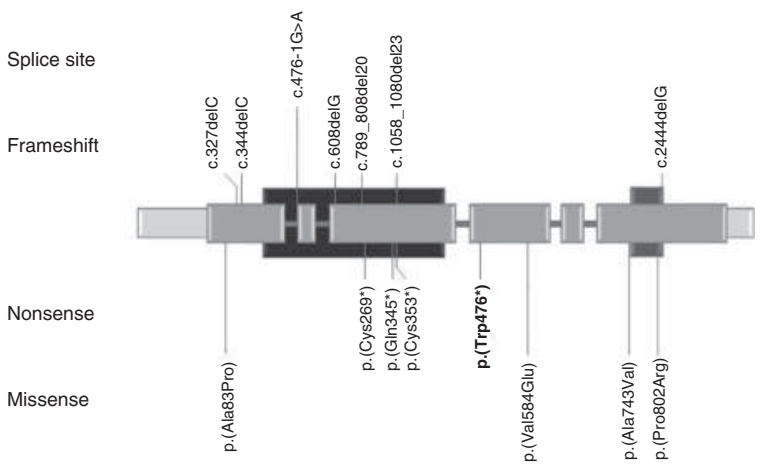

Region of armadillo/B-catenin-like repeats - ARM1 to ARM7 (aa.143 to aa.444) BTB domain (aa.748 to aa.816)

Exons

$5^{\prime}$ and $3^{\prime}$ UTR

\section{Figure 3}

Schematic representation of the $A R M C 5$ gene showing all variants identified in this report and their relative position in the gene and function in the protein; the germline mutation is shown in bold. nodules derived from the same patients with PMAH is extraordinary for what is otherwise a benign disorder. Only mutations associated with DNA and/or chromosomal instability are known to cause such diversity in missense substitutions on the protein function. pre-malignant conditions, the prime example of this being pre-malignant polyps in patients with $A P C$ or $M Y H$ mutations (17). The issue of the need for bi-allelic, or whether monoallelic inactivation of genes like $M L H 1$, $M S H 2$, and $M Y H$ is sufficient to induce colonic tumorigenesis, is still under considerable debate in the literature; existing guidelines recognize the association of specific phenotypes with single (dominant) and dual (recessive) losses, respectively (18).

What is remarkable in ARMC5's multiple and extensive mutability is that PMAH is a benign disorder with no known cases of this disease ever progressing to adrenocortical cancer. Preliminary studies showed a possible TSG function for ARMC5 as a protein that induces apoptosis (of the H295R cancer cell line) $(8,19)$. Thus, ARMC5 inactivation leads to resistance to apoptosis in adrenocortical cells, which apparently leads to hyperplasia. However, the absence of malignancy also suggests that $A R M C 5$ inactivation does not cause a metastatic, aggressive cellular phenotype.

In conclusion, in this case study we document extensive genetic variance of ARMC5 in a single patient with PMAH. This adds to the existing body of evidence of extreme mutability of the ARMC5 gene whose function remains to be determined in animal models and in in vitro studies.

Table 2 Mutations found in the patient described here, and in silico modeling prediction of the effect of the respective ARMC5

\begin{tabular}{|c|c|c|c|c|c|c|c|c|c|}
\hline \multirow[b]{2}{*}{ DNA change } & \multirow[b]{2}{*}{ Protein change } & \multirow[b]{2}{*}{ Exon } & \multirow[b]{2}{*}{ Domains } & \multicolumn{2}{|c|}{ In silico modeling } & \multicolumn{4}{|c|}{ Inter-species alignment } \\
\hline & & & & Prediction & Score $^{a}$ & $\begin{array}{c}\text { Mus } \\
\text { musculus }\end{array}$ & $\begin{array}{c}\text { Dasypus } \\
\text { novemcinctus }\end{array}$ & $\begin{array}{l}\text { Xenopus } \\
\text { tropicalis }\end{array}$ & $\begin{array}{c}\text { Petromyzon } \\
\text { marinus }\end{array}$ \\
\hline c. $247 \mathrm{G}>\mathrm{C}$ & p.(Ala83Pro) & 1 & NTD & Damaging & 1.000 & A & - & $A$ & $A$ \\
\hline c.327delC & p. (Ala110Profs*27) & 1 & NTD & Frameshift & & & & & \\
\hline c.346delT & p. $($ Ser116Argfs $* 21)$ & 1 & NTD & Frameshift & & & & & \\
\hline c. $476-1 \mathrm{G}>\mathrm{A}$ & Splice & Intron 1 & Armadillo & Splice site & & & & & \\
\hline c. $608 \mathrm{delG}$ & p. (Ser203Thrfs*2) & 3 & Armadillo & Frameshift & & & & & \\
\hline c.789_808del20 & p.(Glu264Profs*5) & 3 & Armadillo & Frameshift & & & & & \\
\hline c. $.807 \mathrm{C}>\mathrm{A}$ & p.(Cys269*) & 3 & Armadillo & Nonsense & & & & & \\
\hline c. $1033 C>T$ & p. $\left(G \ln 345^{*}\right)$ & 3 & Armadillo & Nonsense & & & & & \\
\hline c. $1059 C>A$ & p. $($ Cys353*) & 3 & Armadillo & Nonsense & & & & & \\
\hline c.1059_1080del22 & p. $($ Cys353*) & 3 & Armadillo & Frameshift & & & & & \\
\hline C. $1428 \mathrm{G}>\mathrm{A}$ & p. $(\operatorname{Trp} 476 *)$ & 4 & - & Nonsense & & & & & \\
\hline c. $1751 \mathrm{~T}>\mathrm{A}$ & p.(Val584Glu) & 4 & - & Damaging & 1.000 & V & $\mathrm{V}$ & I & $\mathrm{V}$ \\
\hline c. $2228 \mathrm{C}>\mathrm{T}$ & p.(Ala743Val) & 6 & $\begin{array}{l}\text { BTB/POZ- } \\
\text { like }\end{array}$ & Damaging & 0.703 & A & $A$ & - & - \\
\hline c. $2405 C>G$ & p.(Pro802Arg) & 6 & $\begin{array}{l}\text { BTB/POZ- } \\
\text { like }\end{array}$ & Damaging & 1.000 & $\mathrm{P}$ & $\mathrm{P}$ & $\mathrm{P}$ & L \\
\hline c.2444delG & $\begin{array}{l}\text { p.(Ala815Leuf- } \\
\left.s^{*} 102\right)\end{array}$ & 6 & $\begin{array}{l}\text { BTB/POZ- } \\
\text { like }\end{array}$ & Frameshift & & & & & \\
\hline
\end{tabular}

NTD, n-terminal domain; BTB/POZ-like, BR-C, ttk and bab/pox virus and zinc finger like domain. The letters in the topic 'interspecies alignment' are relative to the amino acid present in the position: $\mathrm{V}$, valine; I, isoleucine; $\mathrm{A}$, alanine; $\mathrm{P}$, proline; $\mathrm{L}$, leucine. ' $-{ }^{\prime}$, no aminoacid present. In bold is the germline mutation. ${ }^{a}$ Scores goes from 0.000 to 1.000 . Greater score indicates higher probability to impair the protein function. The main factors taken into account for the calculation of the score are: i) difference in the thermo-physical properties of the WT and mutant protein; and ii) evolutionary preservation of the residue in the corresponding position. 


\section{Supplementary data}

This is linked to the online version of the paper at http://dx.doi.org/10.1530/ EJE-15-0205.

\section{Declaration of interest}

The authors declare that there is no conflict of interest that could be perceived as prejudicing the impartiality of the research reported.

\section{Funding}

This research was supported by the Intramural Research Program of Eunice Kennedy Shriver National Institute of Child Health and Human Development, and in part by a grant from the Conselho Nacional de Desenvolvimento Científico e Tecnológico (CNPq), Process: 311166/2011-3 - PQ-2 (to F R Faucz).

\section{Acknowledgements}

We thank Diane Cooper, MSLS, NIH Library, for providing assistance in writing this manuscript.

\section{References}

1 Lacroix A. ACTH-independent macronodular adrenal hyperplasia. Best Practice \& Research. Clinical Endocrinology \& Metabolism 200923 245-259. (doi:10.1016/j.beem.2008.10.011)

2 Kirschner MA, Powell RD \& Lipsett MB. Cushing's syndrome: nodular cortical hyperplasia of adrenal glands with clinical and pathological features suggesting adrenocortical tumor. Journal of Clinical Endocrinology and Metabolism 196424 947-955. (doi:10.1210/jcem-24-10-947)

3 Lacroix A, Mircescu H \& Hamet P. Clinical evaluation of the presence of abnormal hormone receptors in adrenal Cushing's syndrome. Endocrinologist 1999 9 9-15. (doi:10.1097/00019616-199901000-00004)

4 Louiset E, Duparc C, Young J, Renouf S, Tetsi Nomigni M, Boutelet I, Libé R, Bram Z, Groussin L, Caron P et al. Intraadrenal corticotropin in bilateral macronodular adrenal hyperplasia. New England Journal of Medicine 2013369 2115-2125. (doi:10.1056/NEJMoa1215245)

5 Hsiao HP, Kirschner LS, Bourdeau I, Keil MF, Boikos SA, Verma S, Robinson-White AJ, Nesterova M, Lacroix A \& Stratakis CA. Clinical and genetic heterogeneity, overlap with other tumor syndromes, and atypical glucocorticoid hormone secretion in adrenocorticotropinindependent macronodular adrenal hyperplasia compared with other adrenocortical tumors. Journal of Clinical Endocrinology and Metabolism 200994 2930-2937. (doi:10.1210/jc.2009-0516)

6 Matyakhina L, Freedman RJ, Bourdeau I, Wei MH, Stergiopoulos SG, Chidakel A, Walther M, Abu-Asab M, Tsokos M, Keil M et al. Hereditary leiomyomatosis associated with bilateral, massive, macronodular adrenocortical disease and atypical cushing syndrome: a clinical and molecular genetic investigation. Journal of Clinical Endocrinology and Metabolism 200590 3773-3779. (doi:10.1210/jc.2004-2377)

7 Elbelt U, Trovato A, Kloth M, Gentz E, Finke R, Spranger J, Galas D, Weber S, Wolf C, König K et al. Molecular and clinical evidence for an ARMC5 tumor syndrome: concurrent inactivating germline and somatic mutations are associated with both primary macronodular adrenal hyperplasia and meningioma. Journal of Clinical Endocrinology and Metabolism 2015100 119-128. (doi:10.1210/jc.2014-2648)

8 Assie G, Libe R, Espiard S, Rizk-Rabin M, Guimier A, Luscap W, Barreau O, Lefèvre L, Sibony M, Guignat L et al. ARMC5 mutations in macronodular adrenal hyperplasia with Cushing's syndrome. New England Journal of Medicine 2013369 2105-2114. (doi:10.1056/ NEJMoa1304603)

9 Gagliardi L, Schreiber AW, Hahn CN, Feng J, Cranston T, Boon H, Hotu C, Oftedal BE, Cutfield R, Adelson DL et al. ARMC5 mutations are common in familial bilateral macronodular adrenal hyperplasia. Journal of Clinical Endocrinology and Metabolism 201499 1784-1792. (doi:10.1210/jc.2014-1265)

10 Almeida MQ, Harran M, Bimpaki EI, Hsiao HP, Horvath A, Cheadle C, Watkins T, Nesterova $\mathrm{M} \&$ Stratakis CA. Integrated genomic analysis of nodular tissue in macronodular adrenocortical hyperplasia: progression of tumorigenesis in a disorder associated with multiple benign lesions. Journal of Clinical Endocrinology and Metabolism 201196 728-738. (doi:10.1210/jc.2010-2420)

11 Bourdeau I, Matyakhina L, Stergiopoulos SG, Sandrini F, Boikos S \& Stratakis CA. 17q22-24 chromosomal losses and alterations of protein kinase a subunit expression and activity in adrenocorticotropin-independent macronodular adrenal hyperplasia. Journal of Clinical Endocrinology and Metabolism 200691 3626-3632. (doi:10.1210/jc.2005-2608)

12 Bourdeau I, Antonini SR, Lacroix A, Kirschner LS, Matyakhina L, Lorang D, Libutti SK \& Stratakis CA. Gene array analysis of macronodular adrenal hyperplasia confirms clinical heterogeneity and identifies several candidate genes as molecular mediators. Oncogene 200423 1575-1585. (doi:10.1038/sj.onc.1207277)

13 Bimpaki EI, Iliopoulos D, Moraitis A \& Stratakis CA. MicroRNA signature in massive macronodular adrenocortical disease and implications for adrenocortical tumourigenesis. Clinical Endocrinology 2010 72 744-751. (doi:10.1111/j.1365-2265.2009.03725.x)

14 Faucz FR, Zilbermint M, Lodish MB, Szarek E, Trivellin G, Sinaii N, Berthon A, Libé R, Assié G, Espiard S et al. Macronodular adrenal hyperplasia due to mutations in an armadillo repeat containing 5 (ARMC5) gene: a clinical and genetic investigation. Journal of Clinical Endocrinology and Metabolism 201499 1113-1119. (doi:10.1210/jc.2013-4280)

15 Alencar GA, Lerario AM, Nishi MY, Mariani BM, Almeida MQ, Tremblay J, Hamet P, Bourdeau I, Zerbini MC, Pereira MA et al. ARMC5 mutations are a frequent cause of primary macronodular adrenal hyperplasia. Journal of Clinical Endocrinology and Metabolism 201499 1501-1509. (doi:10.1210/jc.2013-4237)

16 Lipton L \& Tomlinson I. The genetics of FAP and FAP-like syndromes. Familial Cancer 20065 221-226. (doi:10.1007/s10689-005-5673-3)

17 Lochhead P, Chan AT, Giovannucci E, Fuchs CS, Wu K, Nishihara R, O'Brien M \& Ogino S. Progress and opportunities in molecular pathological epidemiology of colorectal premalignant lesions. American Journal of Gastroenterology 2014109 1205-1214. (doi:10.1038/ ajg.2014.153)

18 Hegde M, Ferber M, Mao R, Samowitz W, Ganguly A \& Working Group of the American College of Medical Genetics and Genomics (ACMG) Laboratory Quality Assurance Committee. ACMG technical standards and guidelines for genetic testing for inherited colorectal cancer (Lynch syndrome, familial adenomatous polyposis, and MYH-associated polyposis). Genetics in Medicine 201416 101-116. (doi:10.1038/gim.2013.166)

19 Berthon A \& Stratakis CA. From $\beta$-catenin to ARM-repeat proteins in adrenocortical disorders. Hormone and Metabolic Research 201446 889-896. (doi:10.1055/s-0034-1389993)
Received 20 February 2015

Revised version received 5 July 2015

Accepted 9 July 2015 